\title{
Evaluation of a Randomized Controlled Trial in the Management of Chronic Lower Back Pain in a French Automotive Industry: An Observational Study
}

\author{
Hala Nassif, MS, Nicolas Brosset, MD, Marion Guillaume, MS, Emilie Delore-Milles, MS, Muriel Tafflet, MS, \\ Frédéric Buchhol, MS, Jean-François Toussaint, MD, PhD
}

ABSTRACT. Nassif H, Brosset N, Guillaume M, Delore-Milles E, Tafflet M, Buchholz F, Toussaint J-F. Evaluation of a randomized controlled trial in the management of chronic lower back pain in a French automotive industry: an observational study. Arch Phys Med Rehabil 2011;92:1927-36.

Objective: To evaluate a specific workplace intervention for the management of chronic lower back pain among employees working in assembly positions in the automotive industry.

Design: Randomized controlled trial.

Setting: On site at the workplace of a French automotive manufacturer.

Participants: Subjects ( $\mathrm{N}=75$ volunteers) were recruited on site and randomly assigned to either an experimental group $(n=37)$ or a control group $(n=38)$.

Intervention: The experimental group followed a supervised 60-minute session, 3 times per week, of muscle strengthening, flexibility, and endurance training during 2 months. The control group received no direct intervention. Evaluation took place at baseline, 2 months, and 6 months.

Main Outcome Measures: Pain related parameters were evaluated using validated questionnaires and scales translated into French (Quebec Back Pain Disability Scale, Rolan Morris Disability Questionnaire, Dallas Pain Questionnaire, and the Tampa Scale for Kinesiophobia). Perceived pain intensity was evaluated using the numerical rating scale, and physical outcome measures were evaluated using specific indicators (flexibility, Biering-Sorensen Test, Shirado test). The multivariate analysis of variance, $t$ test, and Wilcoxon signed-rank test were used for statistical analysis.

Results: We observed a significant beneficial effect $(P<.025)$ for the experimental group at 2 and 6 months in pain parameters, specific flexibility, and in back functions, and a significant improvement at 6 months in the control group for the perceived pain intensity, anterior flexion, flexibility of quadriceps, and Dallas Pain Questionnaire's work recreational score. An increase in the practice of physical activity outside the

From Institut de Recherche bioMédicale et d'Epidémiologie du Sport, Institut National du Sport, de l'Expertise et de la Performance, Paris (Nassif, Guillaume, Tafflet, Toussaint); Université Paris-Descartes, Paris (Nassif, Toussaint); Institut National de la Santé et de la Recherche Médicale, U970, Paris Cardiovascular Research Center-PARCC, Paris (Tafflet); Centre d'Investigations en Médecine du Sport, Hôtel-Dieu, Assistance Publique Hôpitaux de Paris, Paris (Toussaint); and Automobiles psa peugeot Citroën. Service Médecine du Travail, Mulhouse (Brosset, Delore-Milles, Buchholz), France.

No commercial party having a direct financial interest in the results of the research supporting this article has or will confer a benefit on the authors or on any organization with which the authors are associated.

Reprint requests to Hala Nassif, MS, Institut de Recherche bioMédicale et d'Epidémiologie du Sport, Institut National du Sport, de l'Expertise et de la Performance, 11 avenue du Tremblay, 75012 Paris, France, e-mail: hala.nassif@insep.fr.

0003-9993/11/9212-00244\$36.00/0

doi:10.1016/j.apmr.2011.06.029 workplace was noted in both groups at 2 months but persisted at 6 months for the experimental group.

Conclusions: This study reinforces the multiple health benefits of physical activity and physical therapy modalities in the workplace by assisting individuals at risk who have chronic LBP.

Key Words: Exercise; Low back pain; Physical therapy modalities; Rehabilitation; Workplace.

(C) 2011 by the American Congress of Rehabilitation Medicine

$\mathbf{L}$

OW BACK PAIN (LBP) accounts for $56 \%$ of multiple skeletal disorders (MSDs) in the food industry, retail, construction and public work, and personal services. In France, MSDs represent $95 \%$ of occupational disease, and the number of new MSDs has increased by approximately 13\% since 1995 . MSD compensation in 2008 generated a loss of 8.4 million days of work.

During the past years, there has been growing research and practice improvements in the field of lower back pain. Our understanding of LBP and its management has improved after several evidence based-research studies. ${ }^{2}$ Even though numerous surveys on the prevalence of LBP have been published, no significant improvements in decreasing it have been observed. ${ }^{3-6}$ LBP is still a major concern in public health policies within the 45- to 65-year age group and is one of the most frequently reported medical reasons for work loss. ${ }^{7}$ Industries may have a large impact in the prevention and management of LBP through the adoption of prevention strategies and practices. The burden of work disability is shared by the worker, the industry, and the general economy.

\section{List of Abbreviations}

\begin{tabular}{|c|c|}
\hline CONT & control group \\
\hline Danx-dep & $\begin{array}{l}\text { impact of work on anxiety and depression } \\
\text { symptoms }\end{array}$ \\
\hline Ddaily & impact of pain on daily activity \\
\hline Dsocial & impact of pain on social activity \\
\hline Dwork-rec & $\begin{array}{l}\text { impact of pain on work and recreational } \\
\text { activity }\end{array}$ \\
\hline EXP & experimental group \\
\hline FFD & finger to floor distance \\
\hline FTD & finger to tip of toes distance \\
\hline HBD & heel-buttock distance \\
\hline KTD & knee to table distance \\
\hline LBP & lower back pain \\
\hline MANOVA & multivariate analysis of variance \\
\hline MSD & multiple skeletal defects \\
\hline NRS & numerical rating scale \\
\hline RMDQ & Roland Morris Disability Questionnaire \\
\hline
\end{tabular}


The relationship between pain, disability, and work offers various fields of study in ergonomics and health-related work issues. Jobs that can lead to or worsen LBP symptoms are those that require highly repeated movements, overexertion, and static work maintained over time. The correlation between physical demands at work and LBP is complex. ${ }^{8}$ Several environmental and personal factors are interrelated in their contribution to the burden of LBP. Risk factors include biomechanical, psychosocial, and individual factors. In addition, several confounding variables such as age, gender, social and psychological status cannot be excluded and should be taken into consideration. The environment and the coping demands of the work are also confounding variables. ${ }^{9}$ Psychological problems can be both risk factors and consequences of chronic LBP, and the elusive nuance is difficult to assess. A low level of education (affecting lifestyle factors) and older age are other associations that might increase the incidence of LBP. ${ }^{10} \mathrm{Cur}-$ rent international strategies for physical activity promotion recommend the implementation of physical activity opportunities within the work settings in order to reach a larger part of the population. ${ }^{11}$ A long period of pain can lead to the development of physical, social, and psychological disabilities. ${ }^{12}$ Thus an early intervention and a prevention strategy are essential to avoid entering the vicious cycle of LBP, in which pain causes fear of movement, which in turn worsens the original state of LBP because of physical deconditioning and thus causes more pain onward. Although key risk factors have been identified, the incidence of LBP has been increasing during the past years, rendering its management a persistent challenge. ${ }^{13}$ However, a large number of workers with back pain will not engage in a physical activity beneficial for their health because of fear of movement and pain. ${ }^{14}$ It has been proven that any type or form of physical activity with ongoing supervision and long-term follow-up can be successful in treating LBP and preventing its onset. ${ }^{15}$ In fact, effective interventions have been described in several studies, ${ }^{7,16}$ but because of the disparities in methodology, the outcome measures chosen, and the clinical settings, there is a need for more evidence-based quality trials in specific work settings such as factories. Effective management of chronic LBP, which is described by a persistent longterm effect, is an important factor in decreasing the burden of LBP in general. The workplace is a good environment to reach a large proportion of the general population. ${ }^{17}$

The primary objective of the current study was to evaluate the effectiveness of a specific workplace intervention at a car manufacturing company by targeting workers in "at-risk" jobs who have chronic LBP. We tested the hypothesis that a fully supervised workplace intervention results in improvements in physical and pain-related parameters. Through this study, we aimed to promote the importance of on-site interventions for increasing physical activity and managing LBP.

\section{METHODS}

\section{Overview and Study Design}

Workers $(\mathrm{N}=75)$ currently working in the assembly line of a car manufacturing company (Peugeot Citroën Mulhouse) who had chronic LBP took part in the study. All participants signed a written informed consent before the intervention and were assigned by simple randomization into either the experimental group (EXP; $\mathrm{n}=37$ ) or the control group (CONT; $\mathrm{n}=38$ ) accordingly. The random allocation sequencing was generated by the physician with the use of a random number table. The EXP group followed a supervised workplace intervention of exercise and physiotherapy during 2 months. Work- ers were informed of their rights as participants in scientific research according to the Helsinki Declaration.

\section{Inclusion Criteria}

Voluntary workers (men and women) 18 years and older currently working in the assembly department of the Mulhouse site and who had chronic LBP were included in the study.

\section{Exclusion Criteria}

After a medical consultation, patients with recent surgery or serious pathologic conditions related to the onset of LBP or interfering with the designed monitoring measurements (malignant, traumatic, or inflammatory LBP, cardiac or respiratory problems, and severe psychological disorders) were excluded from the study.

\section{Intervention}

Based on the American College of Sports Medicine exercise guidelines (2000 edition) ${ }^{18}$ for muscle strengthening, flexibility training, and cardiovascular endurance, the EXP group performed 60-minute sessions of physical therapy and physical exercise 3 times per week during 2 months. All sessions were administered to groups of 2 to 6 patients and fully supervised by an in-house physical therapist and a physical educator. For organizational purposes within the workplace and for proper supervision, the participants were divided into 3 groups that started the intervention at different stages throughout the year (January, July, and December 2009). The sample size $(\mathrm{N}=75)$ of the experiment was the minimum needed for statistical power (0.8) with effect size (Cohen's $d=.65$ ), and was determined in relation to the previously stated organizational purposes.

The EXP group's sessions focused on training the major muscle groups (see Supplemental Appendix 1, Available online only at the Archives website: www.archives-pmr.org.) The intensity of the exercises during the intervention was personally adapted to each participant, and all the sessions took place within the workplace medical department. The types of exercise performed during the intervention included joint flexion and extension, stretching, stability, coordination, and musclestrengthening exercises. The overall aim was to facilitate movement and to encourage workers to remain physically active and be aware of inappropriate postures or movements that might increase pain and discomfort. Advice to change maladaptive behavior and general advice about healthy lifestyle were also offered. Participants in the CONT group received no direct intervention but were free to consult externally. All participants received medical and paramedical consultation on the benefits of physical activity and proper working posture positions as part of a global workplace policy and strategy.

Physical therapy refers to the warm physiotherapy in which warm packs are used on the physical part in pain $(15 \mathrm{~min}$ at end of session), and exercise refers to the warmup, joint flexion, extension, coordination, muscle strengthening-endurance, and stretching/flexibility (45min per session).

\section{Data Collection Strategy}

A data collection grid was prepared before the beginning of the intervention. Information and measurements were collected by the physician or the physiotherapist on-site and then transferred to the IRMES for statistical analysis while maintaining confidentiality. 


\section{Outcome Measures and Monitoring Criteria}

Demographic characteristics. Collected data were age, body mass index, practice of regular physical activity, and medical history.

Pain and its impact. To evaluate the subjective perceived pain intensity, a numerical rating scale (NRS, 0-10) was used. The impact of pain on different activities was assessed using the Dallas Pain Questionnaire $(0-100 \%)$. The questionnaire is divided into 4 parts: (1) impact of pain on daily activity (Ddaily); (2) impact of pain on work and recreational activity (Dwork-rec); (3) impact of work on anxiety and depression symptoms (Danx-dep); and (4) impact of pain on social activity (Dsocial). Furthermore, the Quebec Back Pain Disability Questionnaire (score, 0-100) and the Roland Morris Low back Pain and Disability Questionnaire (RMDQ; score, 0-24) were also used in the evaluation of the impact of pain in daily life. The Tampa Scale for Kinesiophobia $(0-56)$ was used to measure kinesiophobia (fear of movement).

The use of this large selection of questionnaires was chosen to strengthen our understanding and verify that the changes observed are in accordance and follow a similar trend.

Physical parameters. To evaluate the flexibility of major lower muscles, the muscular hypoextensibility was evaluated for each of the hip flexors, the hamstrings, and the quadriceps. We evaluated the flexibility of the hip flexors by measuring the knee to table distance (KTD) position with the worker lying face down. For the hamstrings, we measured the finger to tip of toes distance (FTD) with the worker sitting on the ground with the legs straight. For the quadriceps, we measured the heelbuttock distance (HBD) with the worker lying face down. All measurements are in centimeters. To estimate the isometric endurance of trunk extensor and abdominal muscles, the Sorensen ${ }^{19}$ and the Shirado endurance tests (in seconds) were chosen. To evaluate overall flexibility, the anterior flexion was measured by the finger to floor distance (FFD). Our decision to measure the above-mentioned physical parameters was in relation to the effect of LBP on gait and the activity of the lumbar erector spinae. ${ }^{20}$

All measurement tools have been previously used and validated in previous studies. ${ }^{21}$ Validated French versions of the questionnaires were used accordingly.

\section{Statistical Analysis}

Data are expressed as mean $\pm \mathrm{SD}$, and qualitative variables as number and percentage.

As a global approach, we performed a multivariate analysis of variance (MANOVA) on each outcome measured. We used outcome measures as dependent variables and the time and group as independent variables. Level of significance was set at a $P$ value of less than .05 .

Outcome measures (baseline, 2 and $6 \mathrm{mo}$ ) were described, and we compared the measurements at 2 months and 6 months with baseline using the Student $t$ test and Wilcoxon test as appropriate, for the 2 groups separately.

Data were analyzed using the R version $2.6 .2^{\mathrm{a}}$ and the SAS software version $9.2 .^{\mathrm{b}}$

\section{Assessment Procedure and Follow-Up}

Detailed physical assessment was carried out by the physician and the physiotherapist at the workplace. Outcome measures were assessed at baseline, 2 months after the start of the intervention, and at 6 months' follow-up. The total mean gain was calculated between the mean score difference at 6 months and at baseline. We excluded subjects with a large amount of missing data; for instance, at 6 months' follow-up, 3 partici- pants in the EXP group and 5 in the CONT group were not included in the analysis.

\section{Interpretation of Results and Thresholds}

A beneficial effect of the intervention leads to a decrease in the scores obtained on the NRS, Dallas questionnaire, Quebec, RMDQ, and Tampa scale and to a decrease in the distance $(\mathrm{cm})$ for the FTD, HBD, and FFD, whereas the KTD $(\mathrm{cm})$ and the Sorensen and Shirado tests (seconds) should increase.

For better interpretation and since there is no consensus for the minimum important difference between groups, we evaluated the results according to different approaches: (1) statistical significance using MANOVA to test the global effect of time and interaction of time by group, and (2) Student $t$ test or Wilcoxon test to evaluate the difference between the 2 time points and baseline.

According to the literature, ${ }^{22-25}$ a $50 \%$ score or greater on the Dallas questionnaire and a score of 40 and above for the Tampa scale are considered pathologic. In general, a 30\% improvement threshold is identified as clinically meaningful.

\section{RESULTS}

\section{Baseline Characteristics}

The mean age was $45.13 \pm 9.1$ years (range, $30-59 y$ ) for the EXP group and $45.3 \pm 8.8$ years (range, $27-60 y$ ) for the CONT group. Demographic data, physical activity practice, and anthropometric measurements are shown in table 1.

The compliance of the subjects at each stage of the study are presented in the CONSORT flowchart diagram in figure 1. There was no statistically significant difference between the 2 groups. Participants who were more compliant and present for the follow-up measurements were younger than the absent or sick ones. The ratio of men to women did not change throughout the study. The most frequent reason for missing data was absence or sickness on the day of the measurement. Subjects could not be reevaluated on another day because of organizational reasons within the company.

\section{Detailed Assessment of Outcome Measures}

In all outcome measures, MANOVA revealed that there were an effect of time and an interaction between time and group, except for 2 measures: the Dsocial and the Shirado test (table 2).

\section{Pain-Related Parameters}

The evolution of pain-related parameters with time and according to group are presented in figures 2 and 3 . The mean scores for all the outcome measures at baseline, 2 months, and 6 months with the $P$ values difference between each times for groups separately are presented in table 3 . The mean scores of flexibility and endurance at each time in both groups are presented in figure 4.

Table 1: Baseline Characteristics of the Study Subjects

\begin{tabular}{lcc}
\hline \multicolumn{1}{c}{ Baseline } & EXP $(\mathrm{N}=37)$ & CONT $(\mathrm{N}=38)$ \\
\hline Age $(\mathrm{y})$ & $45.13 \pm 9.11(30-59)$ & $45.34 \pm 8.80(27-60)$ \\
$\mathrm{BMI}\left(\mathrm{kg} / \mathrm{m}^{2}\right)$ & $25.03 \pm 3.70(19-34)$ & $25.70 \pm 4.61(17-37)$ \\
Women & 11 & 21 \\
Overweight & 35 & 34 \\
Obese & 13.5 & 16 \\
Practice sports & $5(13.51)$ & $6(15.78)$ \\
\hline
\end{tabular}

NOTE. Values are mean \pm SD (range), percentages $(\%)$, or $n(\%)$. Abbreviation: BMI, body mass index. 


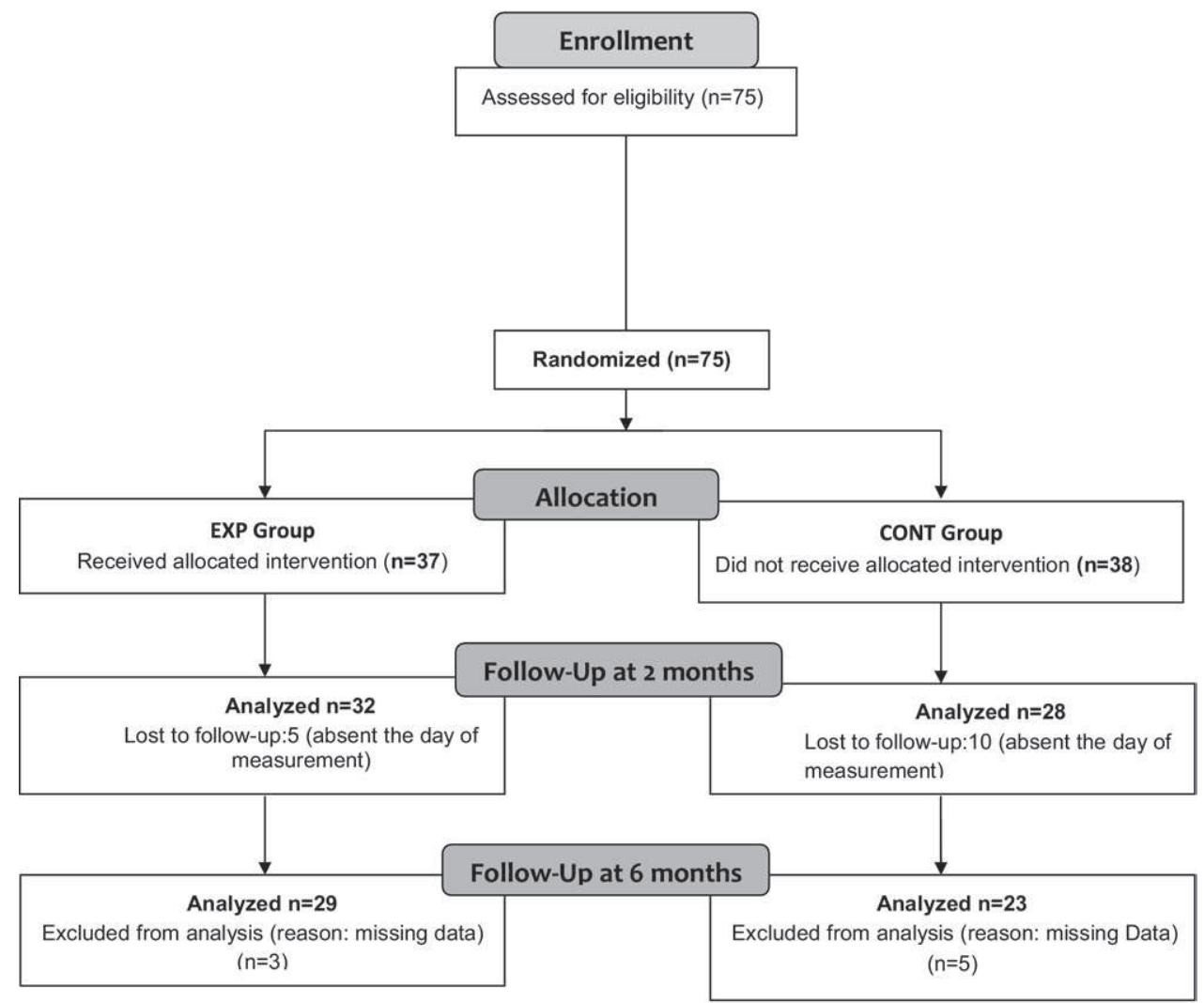

Fig 1. CONSORT flowchart diagram.

Perceived pain (NRS). At 2 months, the total mean difference was significantly lowered compared with the CONT group (1.8 vs .51). At 6 months, however, the total mean difference no longer differed between groups (1.39 and 1.4 for EXP and CONT, respectively).

Kinesiophobia (Tampa scale). We observed a statistically significant decrease in the EXP group at 2 and 6 months. From a clinical viewpoint, 5 subjects in the EXP group and 6 in the CONT group recovered and had a score of less than 40 after 6 months' follow-up. These 11 subjects who recovered had lower scores at baseline. The total mean difference was significantly lowered by 5.12 scale points after 2 months in the EXP group compared with 1.92 in the CONT group. At 6 months, the CONT group's total mean difference compared with baseline was higher than for the EXP group (2.65 vs 2.07) but was not statistically significant

\section{Work and Daily Disability}

RMDQ and Quebec questionnaire. The mean average scores for both questionnaires decreased significantly $(P<.025)$ after the intervention in the EXP group (from 13.91 \pm 4.63 to $9.75 \pm 5.00$ for the RMDQ, and from 40.86 \pm 18.52 to
$26.51 \pm 13.51$ for the Quebec). The CONT group had a general tendency in score amelioration, but it was not statistically significant. The difference between the 2 groups for the RMDQ and Quebec scores is in favor of the EXP group, which decreased by a mean of 2.69 RMDQ points and 9.9 Quebec points at 2 months, and by 2.18 RMDQ points and 7.76 Quebec points more than the CONT group at 6 months.

Dallas Pain Questionnaire (percentage). Ddaily. At 6 months' follow-up, both groups showed a decrease in percentage. The effect was statistically significant for the EXP group at both time points.

Dwork-rec. A statistically significant change was observed for the EXP group at 2 and 6 months and at 6 months for the CONT group.

Danx-dep. The EXP group had, on average, a higher score at baseline compared with the CONT group (44.73 \pm 19.45 vs $36.48 \pm 22.96$ ), with $41 \%$ having a score greater than $50 \%$ at baseline versus $32.4 \%$ in the CONT group. After the intervention at 2 months, the status was reversed. The EXP group had fewer anxiety and depression symptoms, with an average of $30.00 \pm 20.74(23.5 \%)$, while we observed stagnation in the

Table 2: MANOVA $P$ Value Results of All Outcome Measures for Both Groups, Taking Into Consideration the 3 Time Points

\begin{tabular}{|c|c|c|c|c|c|c|c|c|c|c|c|c|c|c|}
\hline & NRS & Quebec & RMDQ & TAMPA & Ddaily & Dwork-rec & Danx-dep & social & HypoH & HypoO & HypoHF & Sorensen & Shirado & A.Incli \\
\hline & & & .0002 & & & & & & & & & & & \\
\hline Tim & .02 & .01 & .007 & .005 & .04 & .07 & $.056 \mathrm{Ns}$ & .79 NS & .0003 & .0045 & $<.0001$ & .006 & $.05 \mathrm{NS}$ & .001 \\
\hline
\end{tabular}

Abbreviations: A.Incli, anterior inclination; HypoH, hypoextensibility of the hamstrings; HypoHF, hypoextensibility of the hip flexors; HypoQ, hypoextensibility of the quadriceps; NS, not significant; TAMPA, Tampa scale. 

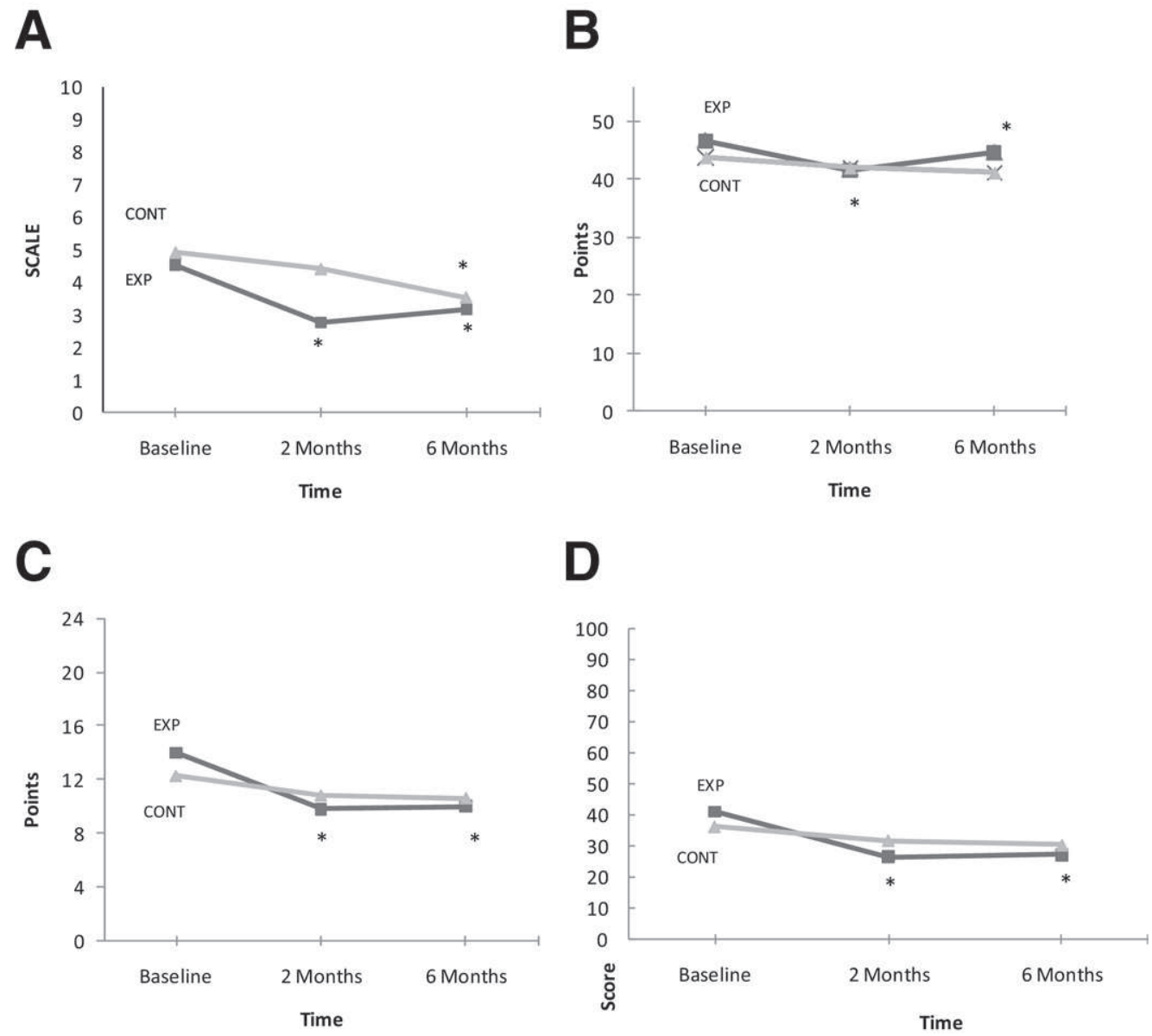

Fig 2. Evolution of pain intensity, kinesiophobia, and work disability with timeThe gray line with triangles represents the CONT group; the black line with a square represents the EXP group. Values are mean \pm SD. An asterisk $(*)$ represents a significant $P$ value. (A) Pain intensity using the NRS $(0-10)$. EXP (baseline: $4.54 \pm 2.73$; 2mo: $2.76 \pm 2.05, P<.001 ; 6$ mo: $3.15 \pm 2.30, P<.01$ ). CONT (baseline: $4.92 \pm 2.35$; 2 mo: 4.41 \pm 2.74 , not significant [NS]; $6 \mathrm{mo}: 3.53 \pm 2.47, P<.01)$. (B) Kinesiophobia using the Tampa scale (0-24). EXP (baseline: $46.71 \pm 6.82 ; 2 \mathrm{mo}$ : 41.59 $\pm 6.93, P<.0001$; $6 \mathrm{mo:} 44.64 \pm 6.72, P<.01$ ). CONT (baseline: $43.82 \pm 8.00 ; 2 \mathrm{mo:} 41.90 \pm 8.50$, NS; $6 \mathrm{mo:} 41.17 \pm 8.28, \mathrm{NS}$ ). (C) Work disability: impact of pain on daily life using the RMDQ (0-24). EXP (baseline: $13.91 \pm 4.63 ; 2 \mathrm{mo:} 9.75 \pm 5.00, P<.0001 ; 6 \mathrm{mo:} 10.03 \pm 5.12, P<.0001)$. CONT (baseline: $12.30 \pm 4.95$; $2 \mathrm{mo}$ : $10.83 \pm 5.65$, NS; $6 \mathrm{mo}$ : $10.60 \pm 5.36$, NS). (D) Work disability: impact of pain on daily life using the Quebec questionnaire $(0-100)$. EXP (baseline: $40.86 \pm 18.52 ; 2 \mathrm{mo}: 26.50 \pm 13.51, P<.0001 ; 6 \mathrm{mo:} 27.15 \pm 13.78, P<.0001$ ). CONT (baseline: $36.16 \pm 17.07$; 2mo: $31.70 \pm 19.57$, NS; $6 \mathrm{mo:} 30.21 \pm 17.26, \mathrm{NS})$.

CONT group (32.3\%). At follow-up we observed a persistent amelioration in the EXP group (15\% having a score $>50)$ and a decrease for the CONT group (17.4\%).

Dsocial. No statistically significant change was observed in either group at 2 or 6 months.

\section{Physical Parameters}

Flexibility. The hypoextensibility for each of the hamstrings (FTD), the quadriceps (HBD), the hip flexors (KTD), and the anterior inclination (FFD) is described below. Results are presented in figure 4.

Hypoextensibility hamstrings (FTD). The mean baseline FTD was not equivalent in both groups. The EXP group had a mean distance of $15.66 \pm 11.12 \mathrm{~cm}$, while the CONT group had a mean distance of $9.51 \pm 8.72 \mathrm{~cm}$. At 2 months, the mean FTD distance increased by $7.94 \mathrm{~cm}$ (statistically significant, $P<.025$ ), and decreased back by $3.42 \mathrm{~cm}$ at 6 months, but remained statistically significant compared with the baseline measurement. The total mean gain was $4.73 \mathrm{~cm}(P<.025)$. The CONT group had a decrease in mean change at 6 months' follow-up, gaining a total of $1.83 \mathrm{~cm}$ (not significant).
Hypoextensibility quadriceps $(H B D)$. Results are significant at both time points for the EXP group and at 6 months for the CONT group. The total mean net gain is $4.73 \mathrm{~cm}$ for the EXP group and $3.53 \mathrm{~cm}$ for the CONT group.

Hypoextensibility hip flexors $(K T D)$. A mean total increase of $3.82 \mathrm{~cm}$ was observed in the EXP group and a decrease of $2.19 \mathrm{~cm}$ in the CONT group at 6 months' follow-up. Results are statistically significant at 2 and 6 months for the EXP group and nonsignificant for the CONT group.

Sorensen and Shirado. The EXP group gained 14.23 seconds in the Sorensen test at 2 months $(P<.025)$ and a total mean gain of 11.92 seconds at follow-up $(P<.025)$, compared with the CONT group that didn't show any differences at either 2 or 6 months.

For the Shirado test, the EXP group showed a significant improvement only at 2 months. For the CONT group results were not significant.

Anterior Inclination (FFD). A statistically significant improvement was observed for the EXP group at 2 and 6 months $(P<.025)$. The results for the CONT group were significant at 6 months. 


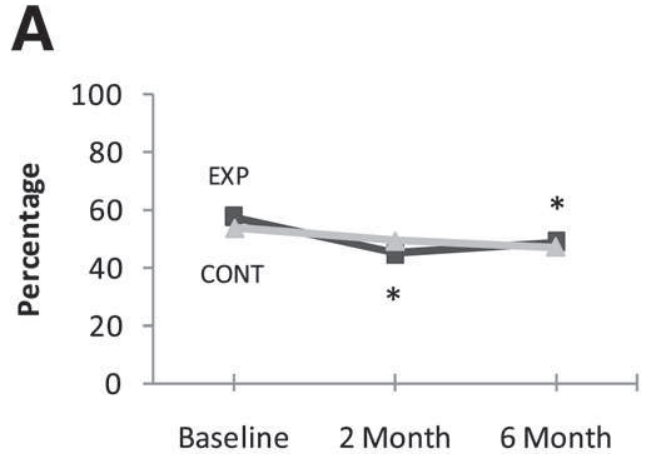

Time

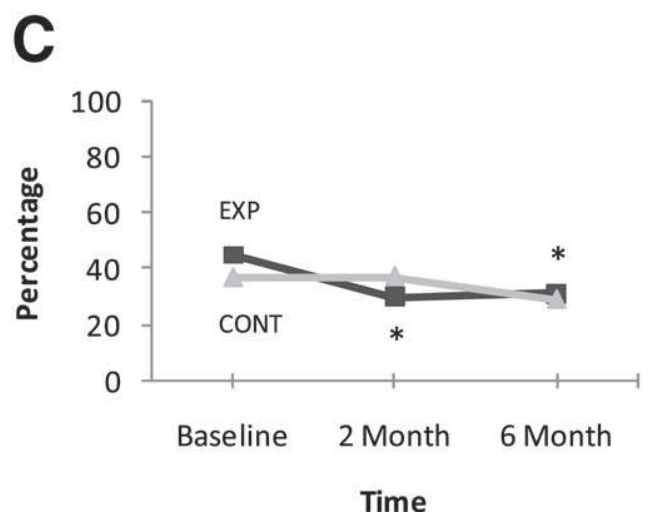

B
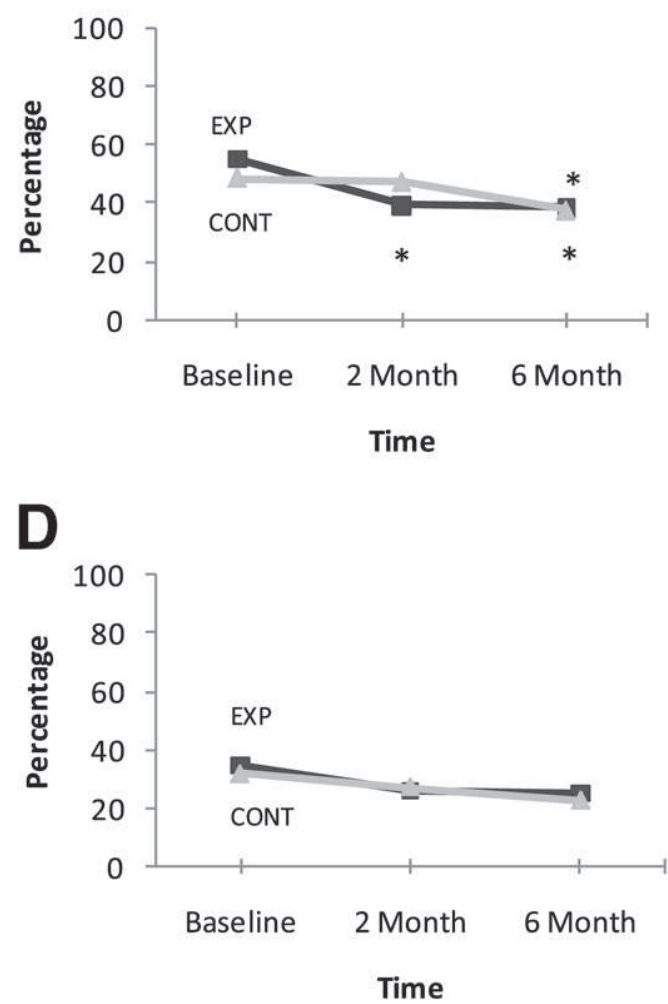

Fig 3. Evolution of the Dallas questionnaire. The gray line with triangles represents the CONT group; the black line with a square represents the EXP group. Values are mean \pm SD. An asterisk $(*)$ represents a significant $P$ value. (A) Impact of pain on daily activity (Ddaily). EXP (baseline: $57.29 \pm 16.19$; $2 \mathrm{mo}$ : $44.55 \pm 17.89, P<.001$; $6 \mathrm{mo}$ : 48.54 $\pm 14.57, P=.01$ ). CONT (baseline: $53.16 \pm 19.57 ; 2 \mathrm{mo}$ : $48.77 \pm 22.36$, not significant [NS]; $6 \mathrm{mo}: 46.78 \pm 20.23$, NS). (B) Impact of pain on work and recreational activity (Dwork-recr). EXP (baseline: $54.85 \pm 20.90 ; 2 \mathrm{mo:}$

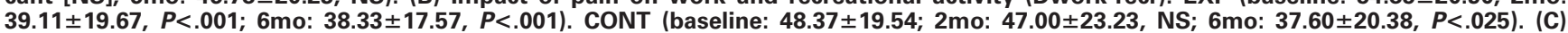
Impact of pain on anxiety and depression symptoms (Danx-dep). EXP (baseline: $44.73 \pm 19.45 ; 2 \mathrm{mo:} 30.0 \pm 20.74, P<.001 ; 6 \mathrm{mo}$ : 31.21 \pm 17.50 , $P=.01$ ). CONT (baseline: $36.48 \pm 22.96 ; 2 \mathrm{mo}: 36.93 \pm 24.10$, NS; 6mo: $28.91 \pm 20.22$, NS). (D) Impact of pain on social activity (Dsocial). EXP (baseline: $34.50 \pm 24.85$; $2 \mathrm{mo}$ : $25.88 \pm 18.68$, NS; $6 \mathrm{mo}$ : $25.30 \pm 20.80$, NS). CONT (baseline: $31.75 \pm 24.07 ; 2 \mathrm{mo}: 27.25 \pm 22.31$, NS; $6 \mathrm{mo}$ : $22.60 \pm 22.09$, NS)

\section{Practice of Physical Activity}

The number of workers who declared that they were practicing a regular leisure-time physical activity increased in both groups. At 2 months, 16 (50\%) of 32 individuals in the EXP group and $9(32.14 \%)$ of 28 in the CONT group were practicing a physical activity. At 6 months, the number increased to 15 $(51.72 \%)$ of 29 individuals in the EXP group and $9(39.1 \%)$ of 23 in the CONT group. The number of workers who declared that they were practicing walking also increased. The increase in the EXP group was from $18.9 \%(7 / 37)$ at baseline to $25 \%$ $(8 / 32)$ at 2 months, to $48.2 \%(14 / 29)$ at 6 months, while the increase in the CONT group was from $10.52 \%$ (4/38) at baseline to $14.28 \%(4 / 28)$ at 2 months, to $21.73 \%(5 / 23)$ at 6 months. The group that started the intervention in July reported a slightly higher rate in the practice of physical activities outside the workplace 2 months after the intervention.

\section{Clinical Relevance}

Improvement was verified according to the $30 \%$ threshold in all parameters. We observed a clinically relevant change in approximately $65 \%$ to $70 \%$ of the participants in the EXP group versus $21 \%$ of the participants in the CONT group after the 2 months of intervention. The results persisted at 6 months' follow-up.

\section{DISCUSSION}

We present an assessment of a physical activity and exercise therapy intervention in the workplace, designed to manage chronic LBP. Our major finding is that the intervention proved to be clinically and statistically relevant in favor of the EXP group at 2 and 6 months. A higher difference in change is observed in the EXP group. Those results are in accordance with the current evidence suggesting that exercise treatment programs and regular physical activity are likely to be beneficial for chronic LBP by decreasing pain severity ${ }^{26-28}$ and reducing physical deconditioning. ${ }^{29-3}$ To our knowledge, there exist few randomized controlled trials investigating the application of LBP management and physical activity promotion recommendations within the workplace. ${ }^{26,32}$ In general, improvement in outcome measures indicates less severe pain, lower disability, and a better overall physical movement, resulting in a positive health impact. Much of the latest available evidence on LBP is in support of interventions that tackle pain effectively.

The effectiveness of this intervention was reflected by a significant decrease in perceived pain intensity (NRS), work disability (RMDQ, Quebec, and Dallas questionnaire), and kinesiophobia (Tampa scale) and an improvement in physical parameters and back-specific functions (anterior inclination, 
Table 3: Mean \pm SD Scores for All Outcome Measures at Baseline, 2 Months, and 6 Months

\begin{tabular}{|c|c|c|c|c|c|c|}
\hline Time & Experimental Group & $\pm \mathrm{SD}$ & $P$ & Control Group & $\pm \mathrm{SD}$ & $P$ \\
\hline \multicolumn{7}{|l|}{ NRS } \\
\hline Baseline & 4.54 & 2.73 & & 4.92 & 2.35 & \\
\hline 2 Months & 2.76 & 2.05 & $<.001^{\ddagger}$ & 4.41 & 2.74 & NS \\
\hline 6 Months & 3.15 & 2.30 & $.005^{\dagger}$ & 3.53 & 2.47 & $.01^{*}$ \\
\hline \multicolumn{7}{|l|}{ TAMPA } \\
\hline Baseline & 46.71 & 6.82 & & 43.82 & 8.00 & \\
\hline 2 Months & 41.59 & 6.93 & $<.001^{\ddagger}$ & 41.90 & 8.50 & NS \\
\hline 6 Months & 44.64 & 6.72 & $.008^{\dagger}$ & 41.17 & 8.28 & NS \\
\hline \multicolumn{7}{|l|}{ RMDQ } \\
\hline Baseline & 13.91 & 4.63 & & 12.30 & 4.95 & \\
\hline 2 Months & 9.75 & 5.00 & $<.001^{\ddagger}$ & 10.83 & 5.65 & NS \\
\hline 6 Months & 10.03 & 5.12 & $<.001^{\ddagger}$ & 10.60 & 5.36 & NS \\
\hline \multicolumn{7}{|l|}{ Quebec } \\
\hline Baseline & 40.86 & 18.52 & & 36.16 & 17.07 & \\
\hline 2 Months & 26.50 & 13.51 & $<.001^{\ddagger}$ & 31.70 & 19.57 & NS \\
\hline 6 Months & 27.15 & 13.78 & $<.001^{\ddagger}$ & 30.21 & 17.26 & NS \\
\hline \multicolumn{7}{|l|}{ Ddaily } \\
\hline Baseline & 57.29 & 16.19 & & 53.16 & 19.57 & \\
\hline 2 Months & 44.55 & 17.89 & $<.001^{\ddagger}$ & 48.77 & 22.36 & NS \\
\hline 6 Months & 48.54 & 14.57 & $.01 *$ & 46.78 & 20.23 & NS \\
\hline \multicolumn{7}{|l|}{ Dwork-rec } \\
\hline Baseline & 54.85 & 20.90 & & 48.37 & 19.54 & \\
\hline 2 Months & 39.11 & 19.67 & $<.001^{\ddagger}$ & 47.00 & 23.23 & NS \\
\hline 6 Months & 38.33 & 17.57 & $<.001^{\ddagger}$ & 37.6 & 20.38 & $.01^{*}$ \\
\hline \multicolumn{7}{|l|}{ Danx-dep } \\
\hline Baseline & 44.73 & 19.45 & & 36.48 & 22.96 & \\
\hline 2 Months & 30.00 & 20.74 & $<.001^{\ddagger}$ & 36.93 & 24.10 & NS \\
\hline 6 Months & 31.21 & 17.50 & $.002^{\dagger}$ & 28.91 & 20.22 & NS \\
\hline \multicolumn{7}{|l|}{ Dsocial } \\
\hline Baseline & 34.50 & 24.85 & & 31.75 & 24.07 & \\
\hline 2 Months & 25.88 & 18.68 & $>.05$ & 27.25 & 22.31 & NS \\
\hline 6 Months & 25.30 & 20.80 & $>.05$ & 22.6 & 22.09 & NS \\
\hline \multicolumn{7}{|l|}{ Нуро.Н } \\
\hline Baseline & 15.66 & 11.12 & & 9.51 & 8.72 & \\
\hline 2 Months & 7.72 & 8.10 & $<.001^{\ddagger}$ & 9.5 & 9.70 & NS \\
\hline 6 Months & 11.14 & 10.46 & $.043^{*}$ & 7.68 & 9.69 & NS \\
\hline \multicolumn{7}{|l|}{ Hypo.Q } \\
\hline Baseline & 15.05 & 7.41 & & 17.82 & 6.75 & \\
\hline 2 Months & 9.21 & 5.19 & $<.001^{\ddagger}$ & 15.89 & 6.13 & NS \\
\hline 6 Months & 10.32 & 6.48 & $<.001^{\ddagger}$ & 14.29 & 5.75 & $.01^{*}$ \\
\hline \multicolumn{7}{|l|}{ Hypo.HF } \\
\hline Baseline & 13.52 & 5.47 & & 16.52 & 6.04 & \\
\hline 2 Months & 18.81 & 4.43 & $<.001^{\ddagger}$ & 13.85 & 4.98 & NS \\
\hline 6 Months & 17.34 & 3.38 & $<.001^{\ddagger}$ & 14.33 & 5.07 & NS \\
\hline \multicolumn{7}{|l|}{ Sorensen } \\
\hline Baseline & 18.91 & 23.75 & & 21.35 & 29.74 & \\
\hline 2 Months & 33.14 & 32.15 & $<.001^{\ddagger}$ & 22.96 & 39.08 & NS \\
\hline 6 Months & 30.83 & 26.30 & $<.001^{\ddagger}$ & 25.45 & 39.94 & NS \\
\hline \multicolumn{7}{|l|}{ Shirado } \\
\hline Baseline & 19.94 & 20.47 & & 14.38 & 15.80 & \\
\hline 2 Months & 25.29 & 22.09 & $.017^{*}$ & 14.66 & 21.67 & NS \\
\hline 6 Months & 23.06 & 21.11 & $>.05$ & 16.20 & 23.50 & NS \\
\hline A.Incli & & & & & & \\
\hline Baseline & 16.23 & 13.75 & & 14.83 & 16.60 & \\
\hline 2 Months & 10.63 & 10.03 & $<.001^{\ddagger}$ & 13.89 & 15.95 & NS \\
\hline 6 Months & 12.45 & 12.32 & $.005^{\dagger}$ & 7.75 & 11.67 & $.001^{\dagger}$ \\
\hline PA & & & & & & \\
\hline Baseline & 0.13 & 0.34 & & 0.16 & 0.37 & \\
\hline 2 Months & 0.45 & 0.50 & $<.001^{\ddagger}$ & 0.29 & 0.46 & $.02 *$ \\
\hline 6 Months & 0.48 & 0.50 & $.005^{\dagger}$ & 0.36 & 0.48 & NS \\
\hline Walking & & & & & & \\
\hline Baseline & 0.19 & 0.40 & & 0.10 & 0.31 & \\
\hline 2 Months & 0.23 & 0.43 & $>.05$ & 0.12 & 0.34 & NS \\
\hline 6 Months & 0.45 & 0.50 & $.008^{\dagger}$ & 0.24 & 0.43 & NS \\
\hline
\end{tabular}

Abbreviation: NS, not significant.

${ }^{*} P$ value between .01 and 0.05 , significant; ${ }^{\dagger} P$ value between .001 and .01 , very significant; ${ }^{\ddagger} P$ value $<.001$, extremely significant.

hypoextensibility, Sorensen, and Shirado). Those benefits translate into substantial health gains and are similar to findings in comparable studies. ${ }^{27,32,33}$

The extent of health effects varies between age groups and types of LBP. ${ }^{3}$ In France, epidemiologic studies have been carried out on samples representative of the working population. ${ }^{10}$ There is consensus that efficient workplace interven- tions are highly beneficial for the workers, managers, physicians, and public health representatives. ${ }^{34}$ We evaluated this on-site workplace intervention in quest of understanding realcase scenarios. The strength of this investigation compared with previous studies is that rehabilitation interventions took place at the workplace on workers with chronic LBP rather than in a hospital with patients on sick leave. Furthermore, the 
A

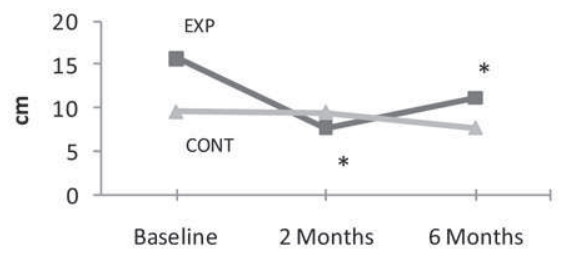

Time

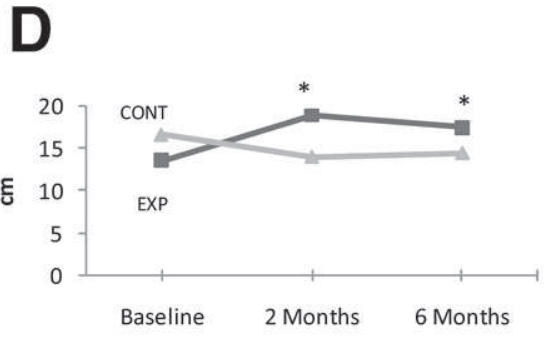

Time
B

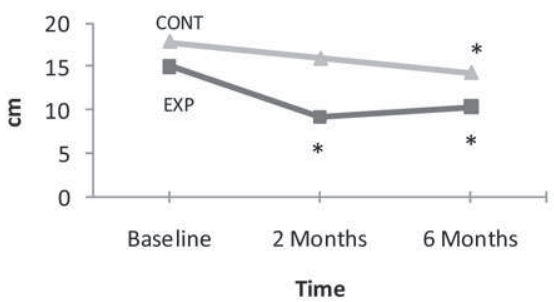

$\mathbf{E}$

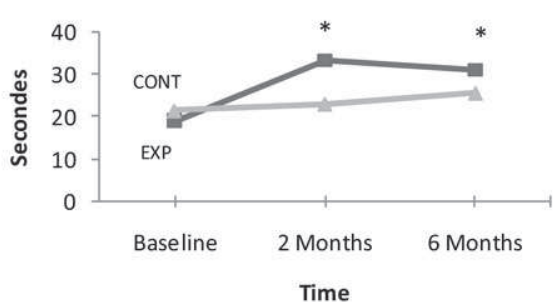

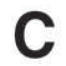
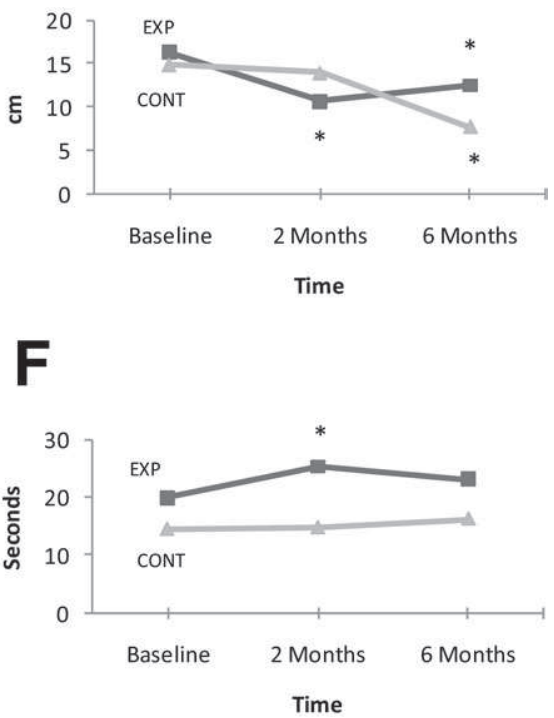

Fig 4. Evolution of flexibility and endurance. The gray line with triangles represents the CONT group; the black line with a square represents the EXP group. Values are mean \pm SD. An asterisk $\left(^{*}\right)$ represents a significant $P$ value. $4 A$ through $4 C$ should decrease for beneficial effect, and 4D through 4F should increase. (A) Flexibility: hypoextensibility of the hamstrings (HypoH) by measuring the FTD. EXP (baseline: 15.66 $\pm 11.12 ; 2 \mathrm{mo}: 7.72 \pm 8.10, P<.0001 ; 6 \mathrm{mo}$ : $11.14 \pm 10.46, P<.01$ ). CONT (baseline: $9.51 \pm 8.72 ; 2 \mathrm{mo}$ : $9.50 \pm 9.70$, not significant [NS]; $6 \mathrm{mo}$ : 7.68 \pm 9.69 , NS). (B) Flexibility: hypoextensibility of the quadriceps (HypoQ) by measuring the HBD. EXP (baseline: 15.05 \pm 7.41 ; $2 \mathrm{mo}$ : 9.21 $\pm 5.19, P<.0001 ; 6 \mathrm{mo:} 10.32 \pm 6.48, P<.0001$ ). CONT (baseline: $17.82 \pm 6.75 ; 2 \mathrm{mo:} 15.89 \pm 6.13, \mathrm{NS} ; 6 \mathrm{mo:} 14.29 \pm 5.75, P<.01$ ). (C) Flexibility: anterior inclination (A.Incli) by measuring the FFD. EXP (baseline: $16.23 \pm 13.75 ; 2 \mathrm{mo:} 10.63 \pm 10.03, P<.0001 ; 6 \mathrm{mo}: 12.45 \pm 12.32, P<.01$ ). CONT (baseline: $14.83 \pm 16.60$; $2 \mathrm{mo}: 13.89 \pm 15.95$, NS; $6 \mathrm{mo}$ : $7.75 \pm 11.67, P<.01$ ). (D) Flexibility: hypoextensibility of the hip flexors (HypoHF) by measuring the KTD. EXP (baseline: 13.52 \pm 5.47 ; $2 \mathrm{mo}$ : 18.81 $\pm 4.43, P<.0001$; $6 \mathrm{mo:} 17.34 \pm 3.38, P<.0001$ ). CONT (baseline: 16.52 $\pm 6.04 ; 2 \mathrm{mo}$ :

13.85 \pm 4.98, NS; $6 \mathrm{mo}$ : 14.33 \pm 5.07 , NS). (E) Endurance of the back muscles using the Sorensen test. EXP (baseline: 18.91 $\pm 23.75 ; 2 \mathrm{mo:}$ 33.14 $\pm 32.15, P<.001 ; 6 \mathrm{mo}: 30.83 \pm 26.30, P<.0001$ ). CONT (baseline: $21.35 \pm 29.74 ; 2 \mathrm{mo}: 22.96 \pm 39.08$, NS; $6 \mathrm{mo:} 25.45 \pm 39.94$, NS). (F) Endurance of the abdominal muscles using the Shirado test. EXP (baseline: 19.94 $\pm 20.47 ; 2 \mathrm{mo:} 25.29 \pm 22.09, P<.025 ; 6 \mathrm{mo}: 23.06 \pm 21.11, \mathrm{NS}$ ). CONT (baseline: 14.38 \pm 15.80 ; 2mo: $14.66 \pm 21.67$, NS; $6 \mathrm{mo}$ : $16.21 \pm 23.50$, NS).

use of a wide variety of outcome measures ${ }^{8,15}$ and the incorporation of a physical activity promotion strategy add value and insight to the study. In a recent cohort study ${ }^{26}$ evaluating the short-term and midterm effectiveness of a retrospective back school (1997-2004), results proved to be positive on pain and functional status but inconclusive on health impact. In addition, a 1-year cognitive-behavioral intervention resulted in a mean improvement of 2.4 points (1.89-2.84) from baseline for the RMDQ. ${ }^{35}$ In our study, a mean change of 3.88 points in the EXP group and 1.70 in the CONT group has been observed at 6 months' follow-up.

Our CONT group had a significant improvement at 6 months for NRS, Dwork-rec, FFD, and FTD, even though the individuals did not go through the intervention. Possible explanations are related to motivational factors resulting from the lack of patient blinding and to their increased predisposition in practicing a form of exercise after seeing their colleagues' change of behavior. Indeed, a number of workers in the CONT group declared that they were taking part in leisure-time physical activity outside the workplace as a form of compensation to the worksite exercise sessions after 2 months $(P<.025)$. The exact duration and type of physical activity have not been analyzed.

The onset of LBP increases the risk of sedentary behavior because of fear of movement and pain, thus resulting with time in a decline of physical fitness, and a negative health impact and quality of life. ${ }^{29,36}$ This reflects the importance of incorporating physical activity in the workplace, especially in jobs associated with an increased risk for LBP. ${ }^{29}$ Individuals af- fected by chronic LBP are most likely to benefit from a physical activity promotion intervention in the workplace. ${ }^{37}$ However, precautionary measures should be taken into account in transmitting the appropriate message of no overexertion and proper behavior modification.

Physical activity in the workplace offers an answer to the management of LBP, since all types of LBP benefit from exercise. ${ }^{33}$ The timing of the intervention in relation to workers' symptoms plays a role in either preventing the onset or the intensity of pain symptoms and disabilities. Scientific research has consistently proven that LBP is a form of age-related disorder because of biomechanical predisposition and postural evolution. It is aggravated or accelerated by several multifactorial events and factors. ${ }^{38}$

The detrimental effects of sedentary behavior are well known in the current literature. On the contrary; a dilemma persists between physical activity and LBP prevalence and severity. The contribution of exercise to the onset and severity of LBP is still debatable. In a recent study ${ }^{29}$ aiming at clarifying the ambiguous evidence, results reveal that participating in physical activity contributes indirectly to the severity of LBP but has no effect on its prevalence.

We excluded workers with severe psychological problems to minimize the confounding variables. An important factor interfering with the analysis is the timing of the intervention that coincides with the peak of the economic crisis, affecting the automotive industry especially hard. Under similar stressful conditions, workers from both groups might have overesti- 
mated their improvement of perceived pain or work ability because they feared negative consequences such as losing their jobs. $^{27}$ The physical parameters are less susceptible to this indirect effect. Despite the presence of similar underlying external uncontrollable factors, which might have affected our results by overestimating some subjective parameters, the statistical difference observed within this limited time in our study is strong and remains promising.

Furthermore, workers in our study showed a high degree of kinesiophobia and work disability scores at baseline. Reviews evaluating different types of physical exercise interventions have reported small to moderate changes in certain outcome measures (pain intensity, return to work, physical parameters), and the progress was clinically more relevant in patients who had lower baseline scores. ${ }^{2}$

Another observation is that the number of workers practicing a form of physical activity outside the workplace (leisure) increased in both groups because they observed the positive impact of exercise on work disability.

From a broad spectrum, our results imply that an intervention combining physical activity promotion and exercise therapy, along with advice on a healthy lifestyle, is effective in the short-term, but needs to be maintained with a form of physical exercise for the benefits to persist. A targeted 2-month intervention at work helps employees decrease perceived pain, kinesiophobia, and work disability and improves their physical parameters more rapidly than leisure-time physical activity and advice alone. Although we observe an insufficient, minimally clinically important change in the NRS scale at 6 months' follow-up, the results of the other outcome measures still imply a positive beneficial impact.

Further research is needed in real work settings to add to these findings, to better understand the functionality and efficiency of physical activity promotion in workers with chronic LBP.

\section{Study Limitations}

Potential limitations in this study are as follows: (1) Because of the complexity of the workplace setting, there could be no patient blinding. (2) The large disparity and multiplicity of variables, the effect of seasonality, ${ }^{39}$ and the restricted small sample size are all underlying factors that might limit the study. (3) The exact duration, type, and intensity of physical activity performed outside the workplace, and information on the exact duration and intensity of pain before the intervention have not been analyzed. Nevertheless, our results reflect a real case scenario with challenges faced when applying recommendations within the workplace.

\section{CONCLUSIONS}

Scientific evidence places the management of LBP as a much more realistic solution to a disorder tightly linked to age. ${ }^{40}$ Our study reinforces the multiple benefits of the promotion of physical activity and physical therapy care in the workplace so as to assist individuals at risk who have LBP. Engaging in an active lifestyle provides protective effects by reducing the negative impact of LBP. ${ }^{34}$ Although the dose-response relationship between exercise intensity level or type and LBP is still inconclusive, our analysis shows that a 2-month intervention of moderate physical activity and exercise therapy generates substantial health gains maintained at 6 months.

The contents of the program are not work specific and can be performed in different groups or settings. The results offer ample opportunities and perspectives.

As such, a similar intervention strategy in the workplace can achieve substantial gain for the individual and the group by decreasing the burden of pain and physical deconditioning. More randomized controlled trials with larger sample sizes are recommended to detect low to medium effect sizes.

Acknowledgments: We thank the Centre National de Développement du Sport and the Ministry of Health, Youth and Sport; INSEP teams for their full support; Mrs. K. Schaal, Mr. G. Berthelot, Mr. A. Sedeaud, and Ms. N. El Helou for carefully reviewing the manuscript; and Mrs. A. S. Godon, A. Briquet, MD, and C. Andlauer, MD, for their input and advice during the intervention.

\section{References}

1. Available at: http://www.travailler-mieux.gouv.fr/Troublesmusculo-squelettiques-TMS.html. 2008; Ministère du Travail, de l'Emploie et de la Santé, Les chiffres Clefs. Accessed June, 2010.

2. van Middelkoop M, Rubinstein SM, Verhagen AP, Ostelo RW, Koes BW, van Tulder MW. Exercise therapy for chronic nonspecific low-back pain. Best Pract Res Clin Rheumatol 2010;24:193204.

3. Rossignol M, Rozenberg S, Leclerc A. Epidemiology of low back pain: what's new? Joint Bone Spine 2009;76:608-13.

4. Dagenais S, Caro J, Haldeman S. A systematic review of low back pain cost of illness studies in the United States and internationally. Spine J 2008;8:8-20.

5. Dunn KM, Croft PR. Epidemiology and natural history of low back pain. Eura Medicophys 2004;40:9-13.

6. Denis D, St-Vincent M, Imbeau D, Jetté C, Nastasia I. Intervention practices in musculoskeletal disorder prevention: a critical literature review. Appl Ergon 2008;39:1-14.

7. Waddell G, Burton AK. Occupational health guidelines for the management of low back pain at work: evidence review. Occup Med (Lond) 2001;51:124-35.

8. Costa-Black KM, Loisel P, Anema JR, Pransky G. Back pain and work. Best Pract Res Clin Rheumatol 2010;24:227-40.

9. Pfingsten M, Hildebrandt J, Leibing E, Franz C, Saur P. Effectiveness of a multimodal treatment program for chronic low-back pain. Pain 1997;73:77-85.

10. Leclerc A, Gourmelen J, Chastang J, Plouvier S, Niedhammer I, Lanoe J. Level of education and back pain in France: the role of demographic, lifestyle and physical work factors. Int Arch Occup Environ Health 2009;82:643-52.

11. Bauman A, Cavill N, Brawley L. ParticipACTION: the future challenges for physical activity promotion in Canada. Int J Behav Nutr Phys Act 2009;6:89.

12. Karjalainen K, Malmivaara A, van Tulder M, et al. Multidisciplinary biopsychosocial rehabilitation for subacute low back pain in working-age adults: a systematic review within the framework of the Cochrane Collaboration Back Review Group. Spine (Phila Pa 1976) 2001;26:262-9.

13. Kent $\mathrm{P}$, Mjøsund HL, Petersen DHD. Does targeting manual therapy and/or exercise improve patient outcomes in nonspecific low back pain? A systematic review. BMC Med 2010;8:22.

14. Rainville J, Hartigan C, Martinez E, Limke J, Jouve C, Finno M. Exercise as a treatment for chronic low back pain. Spine J 2004; 4:106-15.

15. Negrini S, Fusco C, Atanasio S, Romano M, Zaina F. Low back pain: state of art. Eur J Pain Suppl 2008;2:52-6.

16. Caroly S, Coutarel F, Landry A, Mary-Cheray I. Sustainable MSD prevention: management for continuous improvement between prevention and production. ergonomic intervention in two assembly line companies. Appl Ergon 2010;41:591-9.

17. Conn VS, Hafdahl AR, Cooper PS, Brown LM, Lusk SL. Metaanalysis of workplace physical activity interventions. Am J Prev Med 2009;37:330-9.

18. American College of Sport Medecine. Guidelines for exercise testing and prescription. Philadelphia: Lea \& Febiger; 2000. 
19. Demoulin C, Vanderthommen M, Duysens C, Crielaard J. Spinal muscle evaluation using the Sorensen test: a critical appraisal of the literature. Joint Bone Spine 2006;73:43-50.

20. Lamoth CJ, Meijer OG, Daffertshofer A, Wuisman PI, Beek PJ. Effects of chronic low back pain on trunk coordination and back muscle activity during walking: changes in motor control. Eur Spine J 2006;15:23-40.

21. Calmels P, Béthoux F, Condemine A, Fayolle-Minon I. [Low back pain disability assessment tools] [French]. Ann Readapt Med Phys 2005;48:288-97.

22. Wilhelm F, Fayolle-Minon I, Phaner V, et al. Sensitivity to change of the Quebec Back Pain Disability Scale and the Dallas Pain Questionnaire. Ann Phys Rehabil Med 2010;53:15-23.

23. Ostelo RW, de Vet HC. Clinically important outcomes in low back pain. Best Pract Res Clin Rheumatol 2005;19:593-607.

24. Nicholas MK, Asghari A, Blyth FM. What do the numbers mean? Normative data in chronic pain measures. Pain 2008;134:158-73.

25. Jordan K, Dunn KM, Lewis M, Croft P. A minimal clinically important difference was derived for the Roland-Morris Disability Questionnaire for low back pain. J Clin Epidemiol 2006;59:45-52.

26. Maurice M, Blanchard-Dauphin A, Laurent P, Thevenon A, Tiffreau V. [Short- and midterm effectiveness of a back school: retrospective cohort study on 328 patients with chronic low back pain from 1997 to 2004] [French]. Ann Readapt Med Phys 2008; 51:292-300.

27. Beaudreuil J, Kone H, Lasbleiz S, et al. Efficacy of a functional restoration program for chronic low back pain: prospective 1-year study. Joint Bone Spine 2010;77:435-9.

28. Liddle SD, Gracey JH, Baxter GD. Advice for the management of low back pain: a systematic review of randomised controlled trials. Man Ther 2007;12:310-27.

29. Jacob T, Baras M, Zeev A, Epstein L. Physical activities and low back pain: a community-based study. Med Sci Sports Exerc 2004; 36:9-15.

30. Vuori IM. Dose-response of physical activity and low back pain, osteoarthritis, and osteoporosis. Med Sci Sports Exerc 2001;33: S551-86; discussion 609-10.
31. Roche G, Ponthieux A, Parot-Shinkel E, et al. Comparison of a functional restoration program with active individual physical therapy for patients with chronic low back pain: a randomized controlled trial. Arch Phys Med Rehabil 2007;88:1229-35.

32. Schonstein E, Kenny D, Keating J, Koes B, Herbert RD. Physical conditioning programs for workers with back and neck pain: a Cochrane systematic review. Spine (Phila Pa 1976) 2003;28: E391-5.

33. Liddle SD, Baxter GD, Gracey JH. Exercise and chronic low back pain: what works?. Pain 2004;107:176-90.

34. Schneider S, Schmitt H, Zoller S, Schiltenwolf M. Workplace stress, lifestyle and social factors as correlates of back pain: a representative study of the German working population. Int Arch Occup Environ Health 2005;78:253-69.

35. Lamb SE, Hansen Z, Lall R, et al. Group cognitive behavioural treatment for low-back pain in primary care: a randomised controlled trial and cost-effectiveness analysis. Lancet 2010; 375:916-23.

36. Manchikanti L. Epidemiology of low back pain. Pain Physician 2000;3:167-92.

37. Krismer M, van Tulder M. Strategies for prevention and management of musculoskeletal conditions. Low back pain (non-specific). Best Pract Res Clin Rheumatol 2007;21:77-91.

38. Tveito TH, Shaw WS, Huang Y, Nicholas M, Wagner G. Managing pain in the workplace: a focus group study of challenges, strategies and what matters most to workers with low back pain. Disabil Rehabil 2010;32:2035-45.

39. Tucker P, Gilliland J. The effect of season and weather on physical activity: a systematic review. Public Health 2007;121:909-22.

40. Snook SH. Work-related low back pain: secondary intervention. J Electromyogr Kinesiol 2004;14:153-60.

\section{Suppliers}

a. R Foundation for Statistical Computing. Available at: http:// www.R-project.org.

b. SAS Institute Inc, 100 SAS Campus Dr, Cary, NC 27513. 